\title{
Política de regularización del hábitat popular urbano: provincia de Buenos Aires y Partido de La Plata, 1983-2015.
}

\author{
Maria Carla Rodriguez \\ Universidad de Buenos Aires - CONICET, Argentina
}

\section{Mariana Relli Ugartamendia}

Tesis defendida en la Universidad Nacional de La Plata. Facultad de Humanidades y Ciencias de la Educación. Doctorado en Geografía.

\author{
Directora: Beatriz Cuenya \\ Codirectora: Patricia Pintos \\ Fecha de la defensa: 28 de septiembre de 2018
}

La tesis se desarrolla a partir de un objeto relevante y que la autora ha delimitado con precisión: el tratamiento de la irregularidad urbana tal como se ha configurado histórica y territorialmente a partir de la reinstalación del ciclo democrático. Da cuenta de los sucesivos gobiernos, políticas, cristalizaciones institucionales e instrumentos dirigidos a la regularización dominial y urbanística en Buenos Aires, la provincia que presentó el mayor despliegue de esta problemática y que es altamente significativa por su peso e impacto para el escenario nacional. A ello agrega el estudio de la dinámica asumida por la ciudad capital, la Plata, en un acertado esfuerzo de articulación multiescalar.

Su enfoque conceptual es sólido, asentado en tradiciones clásicas de los estudios urbanos críticos basados en la teoría marxiana y sólidamente enraizado en sus vertientes regionales latinoamericanas. Se apoya en un estado del arte exhaustivo, que revisita desde las conceptualizaciones clásicas de la marginalidad hasta los aportes que enfocan la relación entre urbanización y capitalismo dependiente. A lo largo de los capítulos construye una interpretación que articula con solvencia las relaciones entre política habitacional y política urbana con sus encuentros y desencuentros.

De este modo, su análisis de la dimensión política de los procesos de producción del hábitat y sus efectos de clase da cuenta, en particular, de las territorializaciones periféricas de la urbanización capitalista, construyendo una explicación consistente del comportamiento de las políticas bajo estudio, de las lógicas que conducen a la adopción de determinados enfoques hegemónicos, así como de las interacciones entre la ciudad formal e informal. Todo ello le permite delinear un hilo rector en torno a los divorcios e inconsistencias del Estado para accionar en el contexto de dichas interacciones. La tesis ofrece así una visión integrada de un periodo amplio (1983-2015) que le permite identificar y caracterizar tendencias persistentes.

Se destaca especialmente el relevamiento exhaustivo y la sistematización rigurosa de los instrumentos de política provincial, una valiosa "Caja de Herramientas" con diversas tablas síntesis, cuadros y mapas útiles y valiosos tanto para la producción de conocimiento como para los diversos actores implicados en la gestión de la problemática. Así mismo, resulta muy apropiado el tratamiento de la articulación escalar y la relación entre la "foto" y la "película" que presenta a lo largo de los capítulos analíticos, y donde de manera muy gráfica y pedagógica logra plasmar sus consecuencias espaciales en la trama urbana y efectos de segregación.

Finalmente, la tesis es contundente al construir una explicación en la cual la persistencia de los lineamientos de políticas de regularización dominial parciales, plagadas de limitaciones y desconectadas de una intervención urbanística integral, a través de los diversos gobiernos, se comprende como parte 
del instrumental de la gestión de la relación entre macroeconomía y gobernanza. El hábitat popular autoproducido y sus sujetos productores se evidencian así como interpelados y sujetados en la lógica del "triple pacto": (a) un pacto de dominación desde el que se intenta garantizar gobernabilidad, b) un pacto funcional o de división social del trabajo en el que se define quiénes son los agentes fundamentales del proceso de acumulación de capital, y c) un pacto distributivo que refiere a quiénes se apropian de los beneficios y de qué modo (Oszlak, 2011 ${ }^{1}$ ).

En esta trama, la reproducción política, ideológica y cultural del formato único "título de propiedad privada", como solución ofrecida a la integración de los barrios autoproducidos, se muestra como persistente política de Estado, más allá y disociada de los pobres desempeños concretos tanto en el plano jurídico como urbanístico y de las condiciones cotidianas de vida de las poblaciones.

\section{Notas}

1. Oszlak, O. (2011). Rol del Estado: micro, meso, macro. VI Congreso de Administración Pública, Asociación Argentina de Estudios de Administración Pública y la Asociación de Administradores Gubernamentales, Resistencia, Chaco. 